Original Research Paper

\title{
Evaluating the Effect of Soil Particle Characterization on Internal Friction Angle
}

\author{
${ }^{1}$ Arezou Rasti, ${ }^{2}$ Hamid Ranjkesh Adarmanabadi, ${ }^{1}$ Maria Pineda and ${ }^{1}$ Jesse Reinikainen \\ ${ }^{1}$ YeDoma Consultants LLC Company, Albuquerque, New Mexico, USA \\ ${ }^{2}$ Department of Mineral Engineering, New Mexico Institute of Mining and Technology, Socorro, USA
}

\author{
Article history \\ Received: 20-01-2021 \\ Revised: 18-02-2021 \\ Accepted: 20-02-2021 \\ Corresponding Author: \\ Arezou Rasti \\ YeDoma Consultants LLC \\ Company, Albuquerque, New \\ Mexico, USA \\ Email: Arezou.rasti@student.nmt.edu
}

\begin{abstract}
One of the critical design parameters used in evaluating soil structure is the friction angle, derived from Mohr's Circle failure criterion. The soil friction angle is an engineering parameter estimated in the laboratory to quantify the soil shear strength in geotechnical applications. This paper indicates an experimental study investigating the impact of particle size on different sandy soils shear strength behavior. The direct shear test equipment is useful for simulating various stress regimes to determine the soil strength by employing a slow moving lateral force to a consolidated sample along a shear plane. A series of direct shear tests were conducted to investigate the interface behavior of soil. Soil samples were selected from different locations in New Mexico, United States. The influence of soil particle size on the soil's shear strength behavior is discussed by performing a series of symmetric direct shear tests according to ASTM D3080 and analyzing the results. To minimize errors, electronic transducers were used to measure vertical and horizontal displacements. DS7 is geotechnical testing software controlling the test by utilizing a data logger. The investigation indicates that the maximum vertical deformation for all different kinds of sandy soils accrued simultaneously. It was concluded that a soil's friction angle is affected by coarse-grained material. Accordingly, sandy soils with bigger particle size record a higher friction angle than soils containing small particles. Furthermore, a non-linear regression analysis was performed to determine the direct relationship between soil's friction angle and soil particle characteristics.
\end{abstract}

Keywords: Soil Structure, Friction Angle, Mohr's Circle Failure, Shear Strength, ASTM D3080, Uniformity Coefficient, DS7

\section{Introduction}

To predict the engineering behavior of the soil, it is a crucial early step to estimate the water content, the Atterberg limits and strength parameters (Rasti et al., 2020). The internal friction angle is an important parameter of soil, the estimated strength can be derived using Mohr's Circle failure criterion. A soil's friction angle describes the shear resistance of a soil with presence of normal effective stress at which shear failure occurs (Mitchell et al., 1972). The friction angle is a common parameter used to quantify the soil shear strength in geotechnical applications, including pavements, earth dams, retaining walls, slope stability, foundation design, pipelines and soil cement stabilization. The soil friction angle can be determined by applying various types of equipment and theoretical methods to resolve states of stress. Common apparatuses include the triaxial stress test, direct shear test and double-punch test (Hasan and Rashid, 2017). Both direct shear and triaxial methods have been widely used to measure the shear strength of soil and rock materials in geotechnical engineering practice. The direct shear test is a simple and common method for design and research to estimate the friction angle and cohesion of materials per ASTM D3080. Direct shear testing has several applications since less time is required to fail and complete the test than the triaxial test (Gan et al., 1988; Lee, 1970; ASTM International, 2011).

The wide application of the direct shear test in evaluating the strength behavior of granular materials over other shear tests is indorsed to their simplicity of 
setup, a short experiment run time, ability to perform the test under different condition (saturation, drainage and consolidation) and ability to determine the residual strength (Maccarini, 1993; Majedi et al., 2020). However, laboratory tests are expensive. It requires expertise to run the test correctly; therefore, it is recommended that the experiment be simulated using numerical methods such as the hybrid discrete-finite element method to study the effective parameters in the direct shear test (Afrazi et al., 2018). The non-uniformity of stress and strain in direct shear test and having rigid boundary condition, which significantly reduces the grain movements made the direct shear test a practical test for strength behavior of granular materials (Sadrekarimi and Olson, 2011).

Numerous factors influence the soil friction angle, such as mineralogical composition, particle size and gradation, particle shape, compaction characterization, confining pressure, roughness, moisture content, void ratio and relative density. Additive materials can improve the soil formations' engineering properties and they can significantly improve the shear strength and tensile strength. For example, geotextile as an additive material can increase the shear strength of sandy soil. Accordingly, the soil stability in slopes will increase by improving its shear strength (Faramarzi et al., 2016; Ranjkesh Adarmanabadi et al., 2020; Mardookhpour and Ooshaksaraie, 2011; Huat et al., 2009; Drews et al., 2020).

Among all these parameters, particle size and shape play a significant role in soil shear strength properties. Several investigations have evaluated the impact of soil particle characteristics on soil shear behavior, which indicates it is still the subject of debate (Cho et al., 2006; Prakasha and Chandrasekaran, 2005; Ranjkesh Adarmanabadi et al., 2021)

Fuggle (2011) conducted a laboratory investigation to determine the effects of size and gradation on sand particles' shear strength. It was observed that sand particle size and gradation significantly affect soil friction angle and dilation angle. The shear behavior of sand and gravel mixtures was conducted on different proportions by applying triaxial tests. Effects of gravel gradation, particle size and particle shape on shear strength were evaluated. The results indicate that the shear strength increased with increasing gravel content greater than $50 \%$ by weight (Fuggle, 2011; Holtz and Gibbs, 1956).

A series of direct shear tests on sand-gravel mixtures were performed by (Simoni and Houlsby, 2006) to find the relation between shearing resistance and grain size distribution of materials. Thus, different amounts of gravel were added to the sand. In the next step, sand and sand-gravel mixtures' strength behavior were compared. The result's analysis showed that friction angle, peak friction angle and dilatancy at failure increased by gravel addition even with gravel fraction less than 0.1 by volume (Simoni and Houlsby, 2006).

Particle size distribution is an important parameter influencing the shear strength behavior of granular materials. Direct shear box testing was performed on sets of mixtures of fines and mixtures of fines with gravel to investigate the effects of particle size and shape on soils' strength behavior. The results illustrated that the fine fraction experienced less friction angle due to particle alignment and densification. On the other hand, friction angle increased as coarse particles increase and rising elongation or decreasing convexity caused an extra increment in friction angle $(\mathrm{Li}, 2013)$.

Vangla and Latha (2015) reported the results of direct shear and interface direct shear tests on three different size fraction sands with similar morphological characteristics to eliminate the particle's size effect on the friction and interfacial shear strength of sands. The results indicated that particle size has no impact on peak shear strength and interface shear strength for the test conducted on sands with similar morphology at the same void ratio. It was also observed as particle size increased, the ultimate friction angle and the shear bands' thickness increased (Vangla and Latha, 2015).

Prakasha and Chandrasekaran (2005) conducted onedimensional consolidation and Triaxial Shear tests to survey marine sand-clay mixtures' behavior at different proportions. It was concluded from the experiments that an increase in sand grains caused a reduction in void ratio and undrained shear strength and an increase in friction angle and pore pressure.

This study aims to determine the effect of particle size characteristics on the friction angle of sandy soil materials. For this purpose, the friction angle of different sets of comparable samples with different particle size fractions by utilizing a direct shear test was estimated. All tests were conducted on a soil specimen cut from a sample in natural moisture conditions from different New Mexico states' target places. Direct shear tests for each sample took place on three different specimens taken from the same sample at increasing consolidation loads. To minimize the error of the experiment, electronic transducers were employed to measure vertical and horizontal displacements. The direct shear test was controlled by DS7, geotechnical testing software connecting to the data logger.

\section{Methodology}

Several investigations were performed to study the soil particle size's effect on their shear strength under direct sliding conditions. For example, the study was conducted by Vangla and Gali to investigate the impact of particle size of sand and the surface asperities of 
reinforcing material on the interlocking soil mechanism. Their investigations proved that the peak interfacial friction and dilation angles are dependent upon the interlocking between the sand particles and the relative size of sand particles and asperities (Vangla and Gali, 2016). This investigation aims to determine the consolidated drained shear strength of several soils under direct shear boundary conditions to evaluate the effect of particle size on their shear strength.

\section{Design of Test Setup}

The conventional direct shear test is a popular test to determine the mechanical behavior of interfaces and estimate fundamental parameters such as friction angle (Vangla and Gali, 2016; Bacas et al., 2015; Rouse et al., 2008; Bergado et al., 2006).

The direct shear test was conducted according to ASTM D3080 (ASTM International, 2011).

The direct shear test is designed to provide an idea of soil strength by employing a force to a consolidated sample along a shear plane. Shear stress and displacements were nonuniformly distributed within the specimen. Direct shear measures the peak strength of the soil before failure. The test is conducted on a soil specimen cut from a sample in natural moisture conditions. The sample is housed in a square shear box with rigid walls with $15.59 \mathrm{in}^{2}$ area. A porous plate sits above and below the sample, allowing water to flow in and out under saturation and consolidation conditions (Fig. 1).

The shear box is split into two halves, fixed in position and the other connected to the drive mechanism, free to move across the fixed part under shearing conditions. The two halves are fixed to each other with securing screws during the consolidation phase of the test (Fig. 1).

In this investigation, the tests were performed in a natural moisture condition. Direct shear tests took place on three different specimens taken from the same sample and for each sample, the consolidation load applied is increased. Consequently, the results from tests are grouped in a combined report. In the consolidation stage, the load is applied to the sample through the slotted weights via a level arm with a fixed ratio of 10:1.

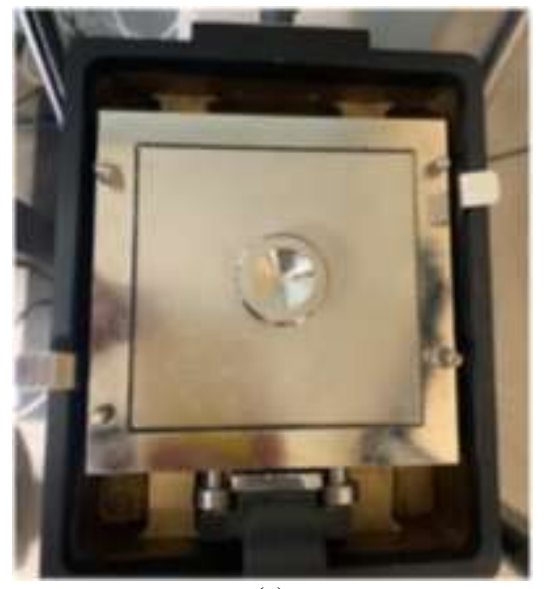

(a)

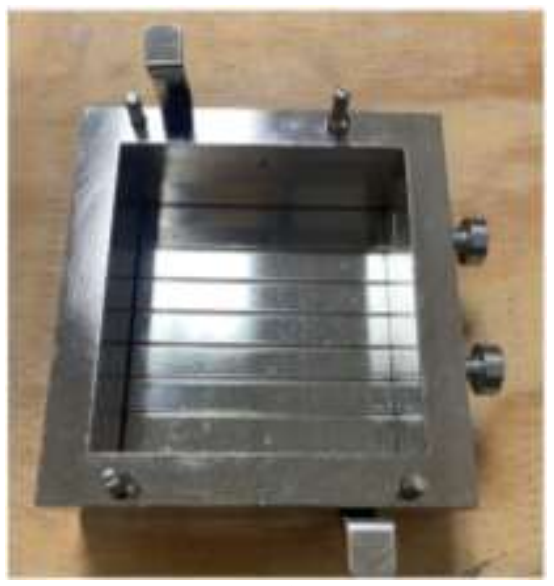

(b)

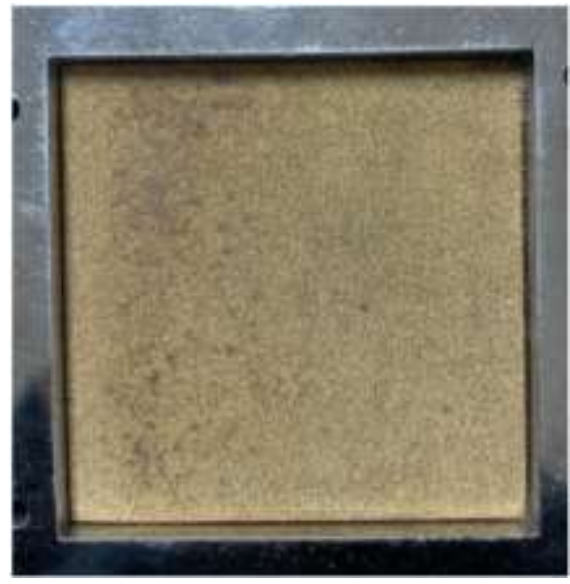

(c)

Fig. 1: (a) Direct shear box container; (b) Direct shear box; (c) Porous plate 
Electronic transducers measured vertical and horizontal displacements of the sample in automatic data collection systems. To control the test, DS7 software was used utilizing a data logger. DS7 is geotechnical testing software that provides a test option for the direct shear test. In this study, DS7 version 3 that ELE generated was used. A stepper motor-driven gearbox applied force by allowing shearing speeds of 0.00001-90.9999 mm/min.

\section{Sample Preparation and Testing}

For this investigation, different types of soil were selected and three tests were performed on specimens from one soil sample. Soil samples were selected from different locations in New Mexico, United States. Figure

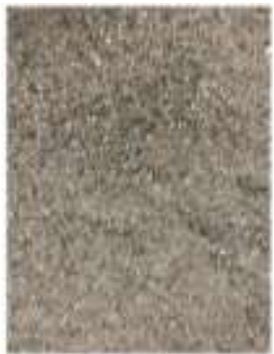

(a)

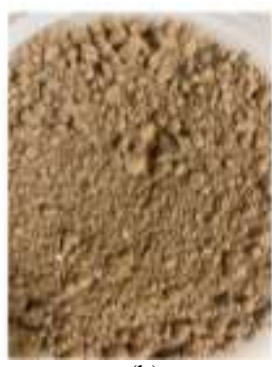

(b)

$2 \mathrm{a}$ to $2 \mathrm{~d}$ present the soil used for this study. A series of laboratory tests were performed on samples to determine the soil engineering properties. Samples were tested for engineering properties as presented in the Table 1 (ASTM International, 2015; 2017a-c).

Grain size distribution curves for soils were obtained per ASTM D6913-04 and the results are presented in Fig. 3. Properties of these soils are given in Table 2. The median size $\left(D_{50}\right)$ of materials is estimated and ranged between 0.080 and $0.180 \mathrm{~mm}$. To prevent an excess pore water pressure, all tests were performed at a constant and low displacement rate of $1 \mathrm{~mm} / \mathrm{min}$ under three different normal stresses to estimate the shearing response of different materials (Dai et al., 2016).

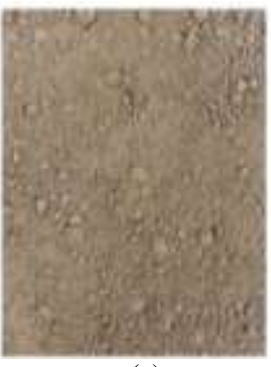

(c)

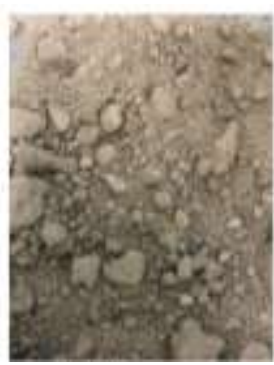

(d)

Fig. 2: (a) Sample 1; (b) Sample 2; (c) Sample 3; (d) Sample 4

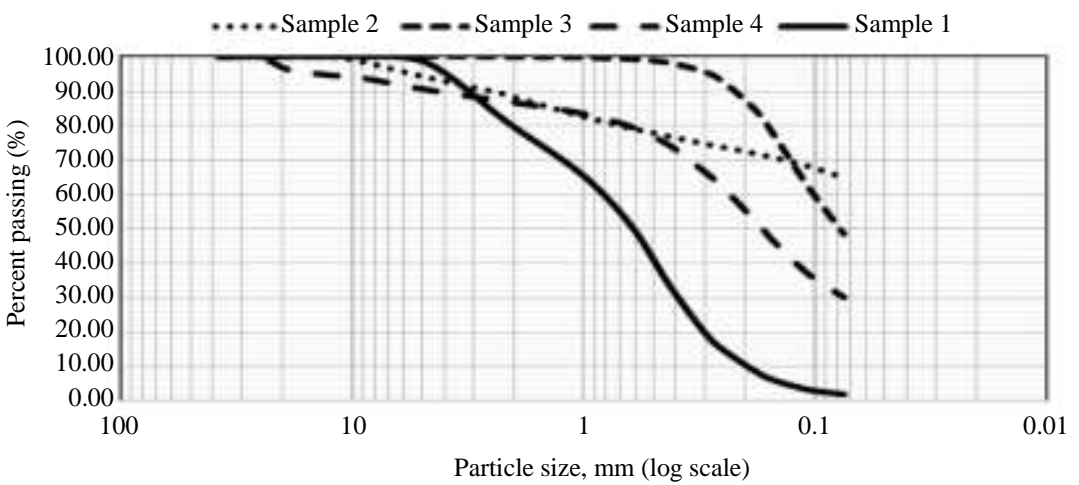

Fig. 3: Particle size distribution curve

Table 1: ASTM standards used in this investigation to define the typical engineering properties

\begin{tabular}{ll}
\hline ASTM Standard & Engineering properties \\
\hline ASTM D6913-04 & Standard test method for particle-size distribution (gradation) of soils using sieve analysis \\
ASTM D2487-17 & Standard practice for classification of soils for engineering purposes (unified soil classification system) \\
ASTM D3282-15 & Standard practice for classification of soils and soil-aggregate mixtures for highway construction purposes \\
ASTM D4318-17 & Standard test methods for liquid limit, plastic limit and plasticity index of soils \\
\hline
\end{tabular}

Table 2: Typical engineering properties of soil samples

\begin{tabular}{|c|c|c|c|c|c|c|c|c|c|c|c|}
\hline Sample ID & Group name & Group symbol & LL (\%) & PL (\%) & PI & $\mathrm{D}_{60}(\mathrm{~mm})$ & $\mathrm{D}_{30}(\mathrm{~mm})$ & $\mathrm{D}_{10}(\mathrm{~mm})$ & $\mathrm{C}_{\mathrm{U}}$ & $\mathrm{C}_{\mathrm{C}}$ & $\mathrm{D}_{50}(\mathrm{~mm})$ \\
\hline S1 & Poorly graded sand & SP & NV & NP & SNP & 0.850 & 0.425 & 0.18 & 4.722 & 1.181 & 0.600 \\
\hline $\mathrm{S} 2$ & Sandy fat clay & $\mathrm{CH}$ & 50 & 15 & 35 & 0.075 & 0.075 & 0.075 & 1.000 & 1.000 & 0.075 \\
\hline $\mathrm{S} 3$ & Silty, clayey sand & SC-SM & 25 & 18 & 7 & 0.109 & 0.075 & 0.075 & 1.357 & 0.737 & 0.080 \\
\hline
\end{tabular}

Note: $\mathrm{D}_{60}=60 \%$ of the soil particles are finer than this size, $\mathrm{D}_{30}=30 \%$ of the soil particles are finer than this size, $\mathrm{D}_{10}=10 \%$ of the soil particles are finer than this size, $\mathrm{D}_{50}=50 \%$ of the soil particles are finer than this size, $\mathrm{C}_{\mathrm{U}}=$ The uniformity coefficient, $\mathrm{C}_{\mathrm{C}}=$ Coefficient of curvature, $\mathrm{PI}=$ Plasticity Index, LL = Liquid Limit 
Table 2 gives the general information about the test series conducted.

The mobilized friction angle relation is (Labuz and Zang, 2012; Heyman, 1972):

$$
|\tau|=C+\sigma \tan \varphi
$$

where, $C$ is cohesion, $\tau$ is the shear stress on plane, $\sigma$ is the normal stress on the plane and $\varphi$ is the angle of the internal friction.

\section{Results and Discussion}

In this study, a series of symmetric loading direct shear tests were completed. All tests were carried out with three samples using different normal pressures. Tests were performed until the shearing resistance achieved the maximum value. The vertical deformation Vs. time of the samples under three different normal stresses are presented in Fig. 4a to 4d. Besides, Fig. 5a to 5d are showing the shear

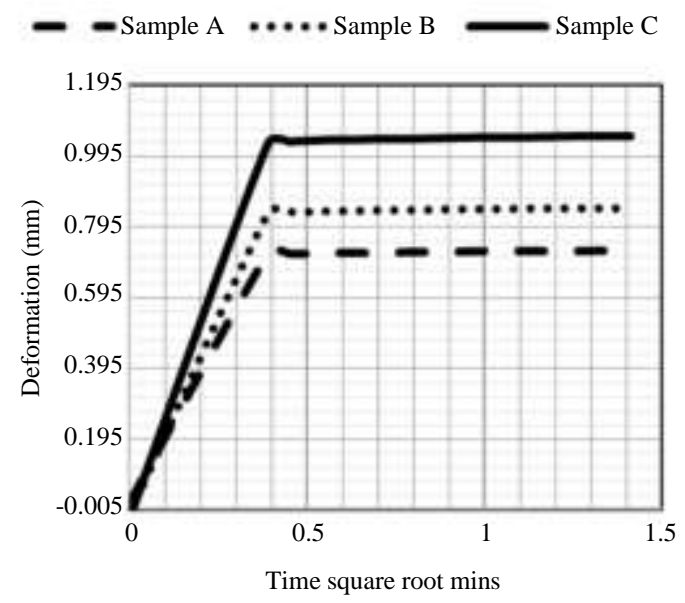

(a)

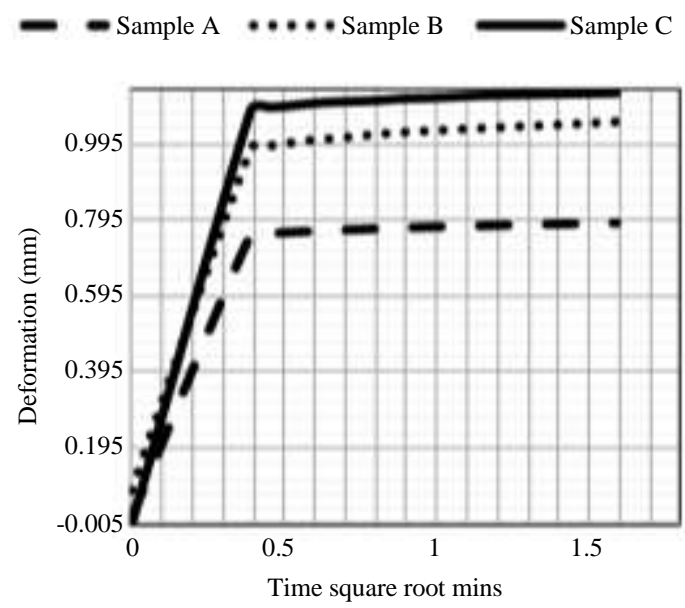

(c) stress vs. the relative lateral displacement. It can be seen that the pattern for all samples is similar. The maximum deformation for all samples is between 0.8 and $2.0 \mathrm{~mm}$. It is concluded that the maximum deformation for all different kinds of sandy soils and applying various normal stresses accrued simultaneously. Maximum deformation for all samples occurred at 0.4 square root minutes regardless of the stress level.

Materials used in the current investigation have different engineering properties and particle size, presented in Table 2. The normal stress applying on uniform samples and the summary of direct shear test for each soil are given in Table 3 to 6 .

Investigating the relationship between measured shear stress failure and normal stress allow estimating the effective shear strength parameters and internal friction angle (Niroumand, 2017). Based on a Mohr-coulomb failure criterion, the slope variation of the shear stress with normal stress is defined as internal friction (Perkins, 2007).

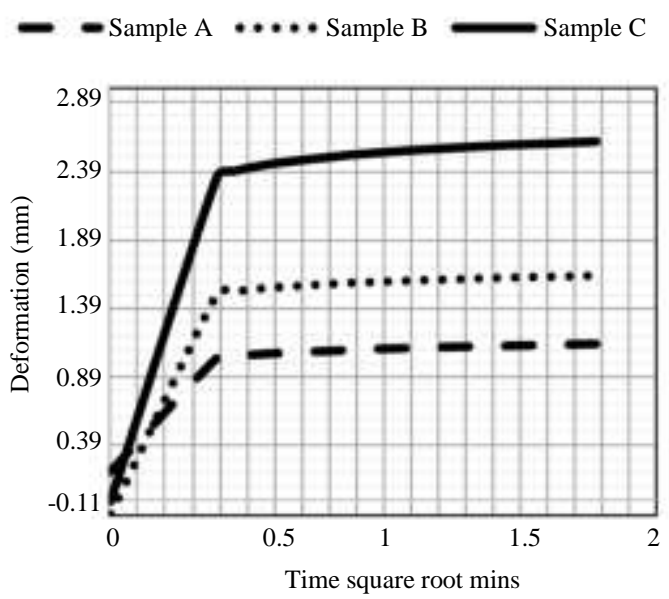

(b)

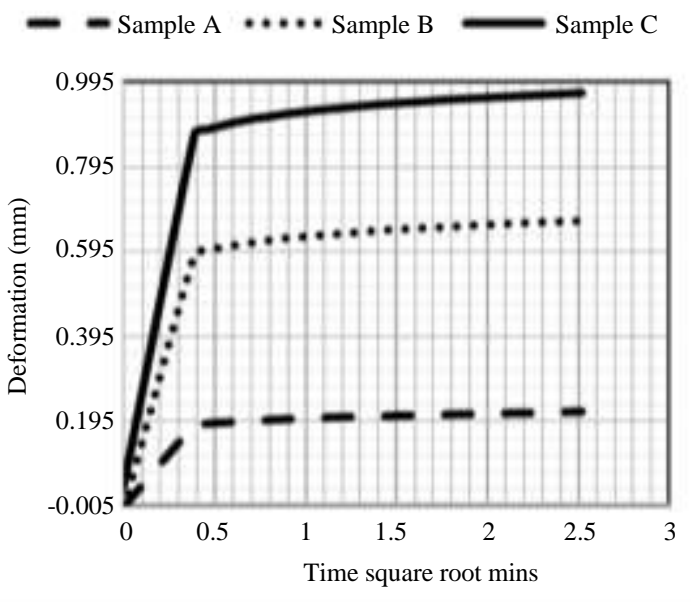

(d)

Fig. 4: (a) Deformation Vs square root time- S1; (b) Deformation Vs square root time- S2; (c) Deformation Vs square root time- S3; (d) Deformation Vs square root time- $\mathrm{S} 4$ 


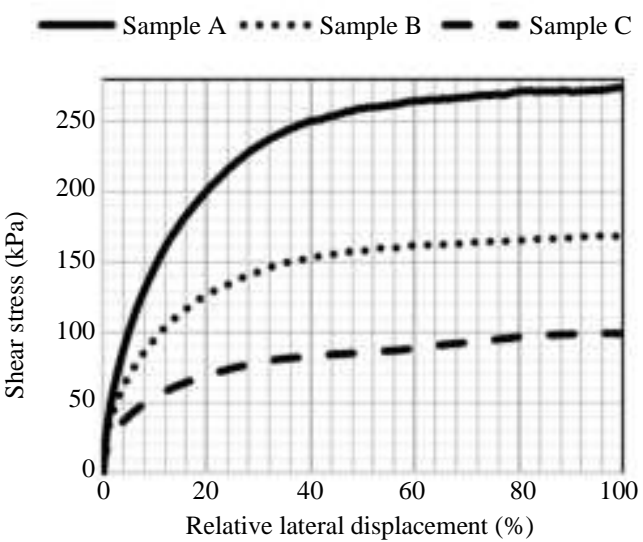

(a)

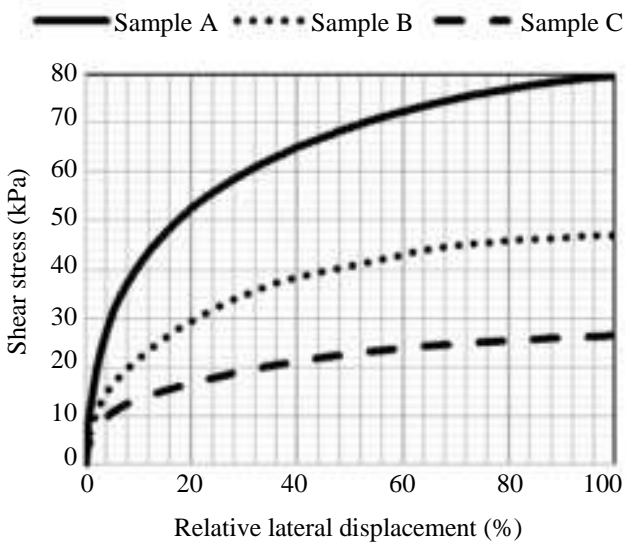

(c)

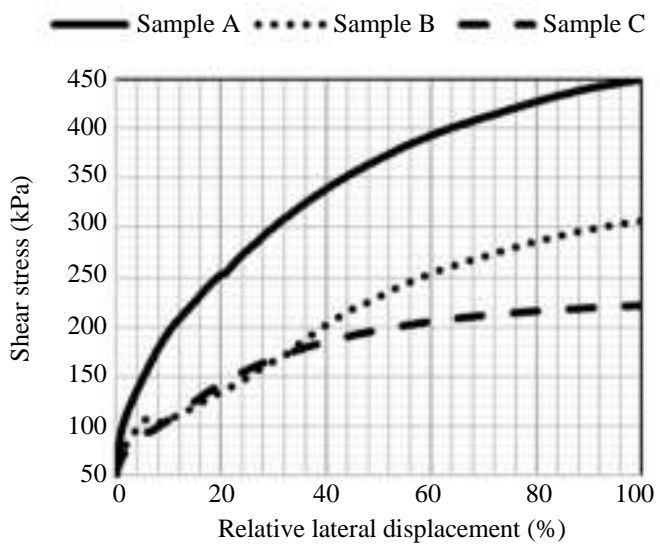

(b)

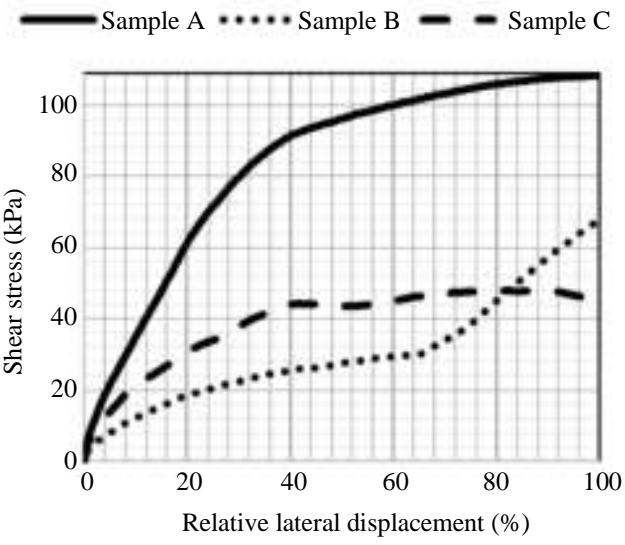

(d)

Fig. 5: (a) Shear stress Vs displacement-S1; (b) Shear stress Vs displacement-S2; (c) Shear stress Vs displacement-S3; (d) Shear stress Vs displacement-S4

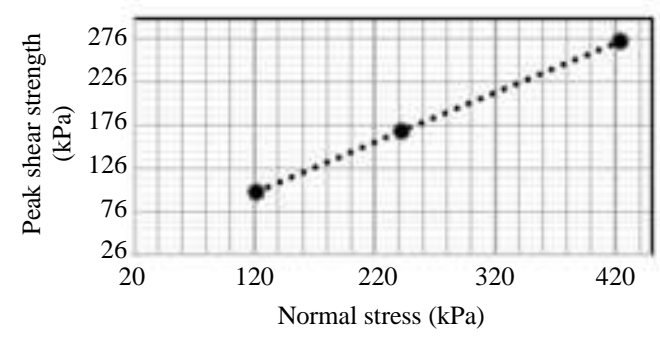

(a)

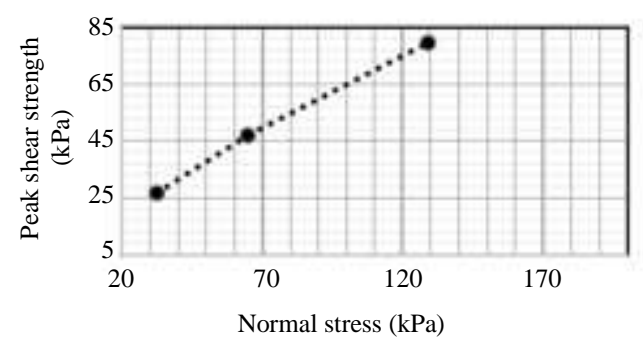

(c)

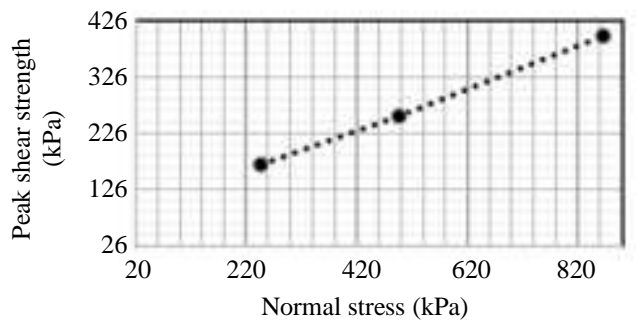

(b)

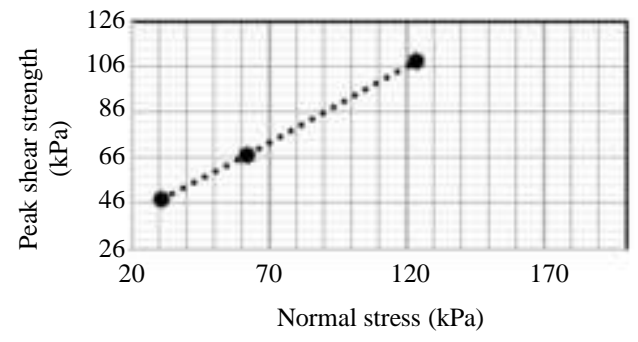

(d)

Fig. 6: (a) Peak shear strength Vs normal stress-S1; (b) Peak shear strength Vs normal stress-S2; (c) Peak shear strength Vs normal stress-S3; (d) Peak shear strength Vs normal stress-S4 
Table 3: Summary of direct shear test- sample S1

\begin{tabular}{llll}
\hline Sample S1 & A & B & C \\
\hline Normal Stress $(\mathrm{kPa})$ & 121.35 & 242.63 & 424.58 \\
Peak Strength (kPa) & 99.49 & 169.13 & 274.07 \\
Corresponding Horizontal Displacement (mm) & 3.57124 & 3.59918 & 3.47472 \\
Rate of Shear Displacement (mm/min) & Stage 1: 0.0995426 & Stage 1: 0.0992124 & Stage $1: 0.0997966$ \\
Final Moisture Content & $5.69 \%$ & $5.69 \%$ & $5.69 \%$ \\
Particle Specific Gravity & 2.65 & 2.65 & 2.65 \\
Final Void Ratio & 0.3522 & 0.4133 & 0.4179 \\
Final Saturation & $42.81 \%$ & $36.46 \%$ & $36.06 \%$ \\
\hline
\end{tabular}

Table 4: Summary of direct shear test- sample S2

\begin{tabular}{llll}
\hline Sample S2 & A & B & C \\
\hline Normal Stress $(\mathrm{kPa})$ & 247.59 & 495.11 & 866.40 \\
Peak Strength (kPa) & 171.47 & 256.97 & 399.21 \\
Corresponding Horizontal Displacement $(\mathrm{mm})$ & 3.62204 & 3.62966 & 3.6068 \\
Rate of Shear Displacement (mm/min) & Stage 1: 0.096266 & Stage 1: 0.0997458 & Stage $1: 0.099619$ \\
Final Moisture Content & $11.99 \%$ & $12.01 \%$ & $12.01 \%$ \\
Particle Specific Gravity & 2.65 & 2.65 & 2.65 \\
Final Void Ratio & 0.9968 & 1.1377 & 1.3998 \\
Final Saturation & $31.88 \%$ & $27.98 \%$ & $22.73 \%$ \\
\hline
\end{tabular}

Table 5: Summary of direct shear test- sample S3

\begin{tabular}{llll}
\hline Sample S3 & A & B & C \\
\hline Normal Stress $(\mathrm{kPa})$ & 32.20 & 64.47 & 128.86 \\
Peak Strength $(\mathrm{kPa})$ & 26.61 & 47.09 & 79.57 \\
Corresponding Horizontal Displacement $(\mathrm{mm})$ & 3.59156 & 3.57124 & 3.53314 \\
Rate of Shear Displacement (mm/min) & Stage 1: 0.099695 & Stage 1: 0.0999236 & Stage $1: 0.099949$ \\
Final Moisture Content & $9.16 \%$ & $9.21 \%$ & $9.17 \%$ \\
Particle Specific Gravity & 2.65 & 2.65 & 2.65 \\
Final Void Ratio & 0.969 & 0.8481 & 0.8315 \\
Final Saturation & $25.05 \%$ & $28.79 \%$ & $29.22 \%$ \\
\hline
\end{tabular}

Table 6: Summary of direct shear test- sample S4

\begin{tabular}{llll}
\hline Sample S4 & A & B & C \\
\hline Normal Stress $(\mathrm{kPa})$ & 30.90 & 61.90 & 123.80 \\
Peak Strength (kPa) & 48.00 & 67.20 & 108.50 \\
Corresponding Horizontal Displacement $(\mathrm{mm})$ & 2.858 & 3.629 & 3.592 \\
Rate of Shear Displacement (mm/min) & Stage 0.1000 & Stage 1: 0.1000 & Stage $1: 0.1049$ \\
Final Moisture Content & $13.03 \%$ & $13.51 \%$ & $13.39 \%$ \\
Particle Specific Gravity & 2.65 & 2.65 & 2.65 \\
Final Void Ratio & 0.9479 & 1.1223 & 1.1712 \\
Final Saturation & $36.44 \%$ & $31.90 \%$ & $30.29 \%$ \\
\hline
\end{tabular}

This investigation's purpose is to evaluate the impact of particle size of different types of sand on shear strength behavior. Several studies proved that the angularity influences the sands' stress-strain response and with increasing the interlocking forces, the peak shear strength will increase (Santamarina and Cho, 2001; Holtz and Kovacs, 1981; Vangla and Latha, 2015; Rouhanifar et al., 2020). It is proved that void ratio has a more considerable effect on the friction angle than the particle size and particle size does not have any effect on the peak friction angle if the void ratio is same.

The result of experiments present in the Fig. 6 a to $6 \mathrm{~d}$.

\section{Statistical Analysis}

As observed from test results, sample no. 1 shows the highest interfacial frictional resistance to the other samples. The following table indicates the comparison of the friction angle of materials used in this investigation. A summary of particle size is presented in Table 7. Results indicated that the angle of friction for material with bigger particle size was steeper than the other soils that contain small particles in the stress range tested. According to the direct shear test results, friction angles were obtained in the range of $20-34^{\circ}$.

Friction angle of the tested material increased with the increasing uniformity coefficient of samples and $D_{50}$ (Fig. 7 and 8). 
Figure 8 displays the results of the friction angle of laboratory tests versus the uniformity coefficient measured. It can be seen that there is a relation between the soil's friction angle and its uniformity coefficient. As $\mathrm{C}_{\mathrm{U}}$ increases, the friction angle will rise.

A non-linear regression analysis was performed to evaluate different soil particle factors' effect on its internal friction angle. Table 8 indicates the relationship between the sandy soil friction angle and its particle characteristics. It is was found a power function with a good coefficient of determination between the soil uniformity coefficient, $\mathrm{D}_{50}$ and their friction angle. As presented in the table, the relationship between friction angle and $\mathrm{C}_{U}$ has the highest coefficient of determination. Consequently, $\mathrm{D}_{50}$ and $\mathrm{C}_{\mathrm{U}}$ of soil can be used to estimate the soil's friction angle while $\mathrm{C}_{U}$ is giving more accurate results.

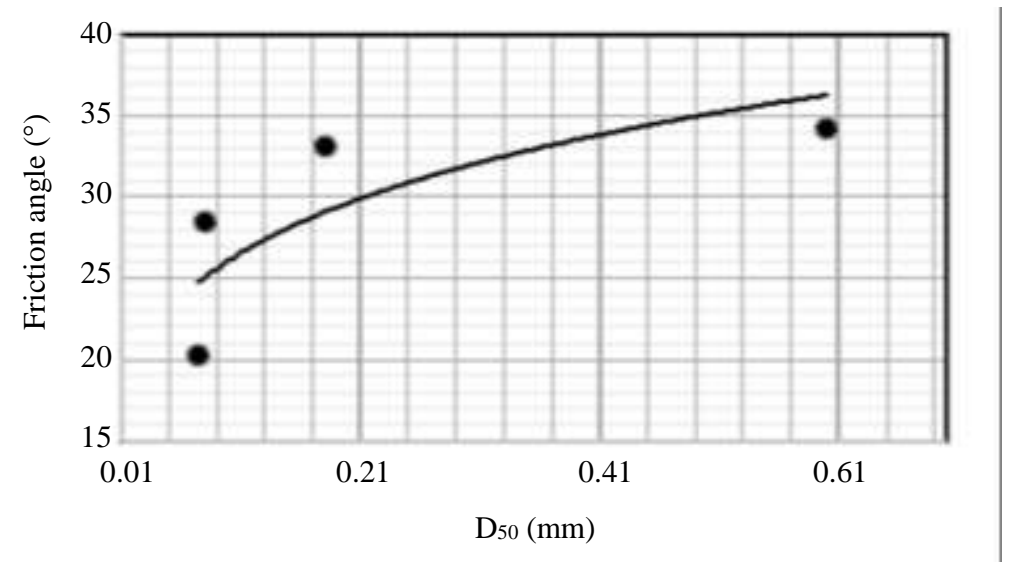

Fig. 7: Friction angle Vs the D50

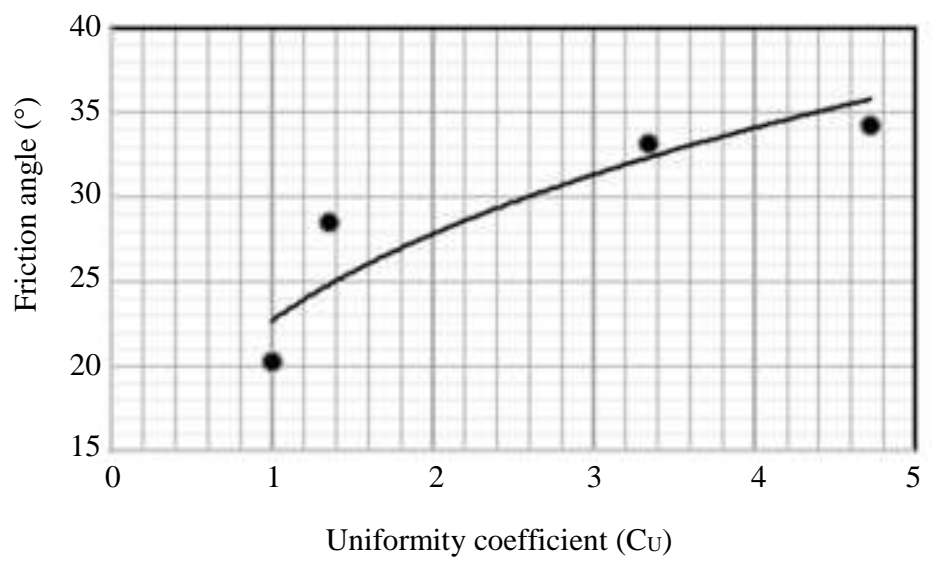

Fig. 8: Friction angle Vs the uniformity coefficient of tested materials

Table 7: Summary of friction angle and D50 material used for study

\begin{tabular}{lll}
\hline Sample ID & D50 $(\mathrm{mm})$ & Friction angle $\left(^{\circ}\right)$ \\
\hline S1 & 0.600 & 34.21 \\
S2 & 0.075 & 20.26 \\
S3 & 0.080 & 28.51 \\
S4 & 0.180 & 33.15 \\
\hline
\end{tabular}

Table 8: Proposed relation between the friction angle and soil particle characteristics

\begin{tabular}{llll}
\hline Dependent variable & Independent variable & Proposed equation & $\mathrm{R}^{2}$ \\
\hline Friction angle & $\mathrm{D}_{50}$ & $39.86 *\left(\mathrm{D}_{50}\right)^{0.184}$ & 0.56 \\
& $\mathrm{C}_{\mathrm{U}}$ & $22.74 *\left(\mathrm{C}_{\mathrm{U}}\right)^{0.293}$ & 0.80 \\
\hline
\end{tabular}




\section{Conclusion}

The effects of particle sizes on the sandy soil's shear strength parameters were studied in this investigation. The relationship between the measured friction angle and different soil particle characteristics of different sandy materials was investigated. Among various factors, the relationship between friction angle with $D_{50}$ and $C_{U}$ was considerable. This investigation proved that the friction angle of soil is affected by the presence of coarsegrained material. It was concluded that there is a direct relationship between friction angle and a soil's uniformity coefficient with a high coefficient of determination. It was observed that the interfacial frictional resistance records a higher value by increasing the uniformity coefficient.

\section{Funding Information}

This research study was funded through YeDoma Consultants, LLC (YeDoma). All material tests in this study were conducted in the firm's full-service geotechnical and construction material testing laboratory in Albuquerque, New Mexico. The authors gratefully acknowledge YeDoma for the support granted.

\section{Author's Contributions}

Arezou Rasti: Contributed to idea development, designing the study, performing the experiments, data preparation and analysis and writing the manuscript.

Hamid Ranjkesh Adarmanabadi: Contributed to design the study, data analysis and writing the manuscript.

Jesse Reinikainen: Contributed to idea development, analyzed the experiment results and review of the manuscript.

Maria Pineda: Contributed to analyze the experiment results and writing and review of the manuscript.

\section{Ethics}

This investigation is original and contains unpublished materials. The authors have read and approved this manuscript and no ethical issues are included.

\section{References}

Afrazi, M., Yazdani, M., Fakhimi, A. A., \& Alitalesh, M. (2018). Numerical analysis of effective parameters in direct shear test by hybrid discretefinite element method. Modares Civil Engineering Journal, 18(3), 13-24. https://www.sid.ir/en/Journal/ViewPaper.aspx ?ID=7 10094

ASTM International. (2011). ASTM D3080/D3080M-11, Standard test method for direct shear test of soils under consolidated drained conditions.
ASTM International. (2015). ASTM D3282-15, Standard practice for classification of soils and soil-aggregate mixtures for highway construction purposes.

ASTM International. (2017a). ASTM D2487-17e1, Standard practice for classification of soils for engineering purposes (unified soil classification system).

ASTM International. (2017b). ASTM D4318-17e1, standard test methods for liquid limit, plastic limit and plasticity index of soils.

ASTM International. (2017c). ASTM D6913/D6913M-17, Standard test method for particle-size distribution (gradation) of soils using sieve analysis.

Bacas, B. M., Canizal, J., \& Konietzky, H. (2015). Frictional behaviour of three crtitical geosynthetic interfaces. Geosynthetics International, 22(5), 355-365. https://doi.org/10.1680/jgein.15.00017

Bergado, D. T., Ramana, G. V., Sia, H. I., \& Varun. (2006). Evaluation of interface shear strength of composite liner system and stability analysis for a landfill lining system in Thailand. Geotextiles and Geomembranes, 24(6), 371-393. https://doi.org/10.1016/j.geotexmem.2006.04.001

Cho, G.-C., Dodds, J., \& Santamarina, J. C. (2006). Particle Shape Effects on Packing Density, Stiffness and Strength: Natural and Crushed Sands. Journal of Geotechnical and Geoenvironmental Engineering, 132(5) 591-602. https://doi.org/10.1061/(ASCE)10900241(2006)132:5(591)

Dai, B. B., Yang, J., \& Zhou, C. Y. (2016). Observed effects of interparticle friction and particle size on shear behavior of granular materials. International Journal of Geomechanics, 16(1). https://doi.org/10.1061/(ASCE)GM.19435622.0000520

Drews, F. A., Rogers, W. P., Talebi, E., \& Lee, S. (2020). The experience and management of fatigue: a study of mine haulage operators. Mining, Metallurgy \& Exploration, 37, 1837-1846. https://doi.org/10.1007/s42461-020-00259-w

Faramarzi, L., Rasti, A., \& Abtahi, S. M. (2016). An experimental study of the effect of cement and chemical grouting on the improvement of the mechanical and hydraulic properties of alluvial formations. Construction and Building Materials, 126 , $23-43$. https://doi.org/10.1016/j.conbuildmat.2016.09.006

Fuggle, A. R. (2011). Geomaterial gradation influences on interface shear behavior. Georgia Institute of Technology.

Gan, J. K. M., Fredlund, D. G., \& Rahardjo, H. (1988). Determination of the shear strength parameters of an unsaturated soil using the direct shear test. Canadian Geotechnical Journal, 25(3), 500-510. https://doi.org/10.1139/t88-055 
Hasan, M. M., \& Rashid, M. A. (2017). Determination of friction angle of soil using double-punch test approach: An experimental study. Cogent Engineering, 4(1). https://doi.org/10.1080/23311916.2017.1419415

Heyman, J. (1972). Coulomb's memoir on statics. Cambridge University Press.

Holtz, R. D., \& Kovacs, W. D. (1981). An introduction to geotechnical engineering. Prentice-Hall, Inc.

Holtz, W. G., \& Gibbs, H. J. (1956). Triaxial shear tests on pervious gravelly soils. Journal of the Soil Mechanics and Foundations Division, 82(1), 1-22.

Huat, B. B. K., Asadi, A., \& Kazemian, S. (2009). Experimental investigation on geomechanical properties of tropical organic soils and peat. American Journal of Engineering and Applied Science, 2(1), 184-188. https://doi.org/10.3844/ajeassp.2009.184.188

Labuz, J. F., \& Zang, A. (2012). Mohr-Coulomb failure criterion. Rock Mech Rock Eng, 45, 975-979. https://doi.org/10.1007/s00603-012-0281-7

Lee, K. L. (1970). Comparison of plane strain and triaxial tests on sand. Journal of the Soil Mechanics and Foundations Division, 96(3), 901-923.

Li, Y. (2013). Effects of particle shape and size distribution on the shear strength behavior of composite soils. Bulletin of Engineering Geology and the Environment, 72, 371-381. https://doi.org/10.1007/s10064-013-0482-7

Maccarini, M. (1993). A comparison of direct shear box tests with triaxial compression tests for a residual soil. Geotechnical \& Geological Engineering, 11(2), 69-80. https://doi.org/10.1007/BF00423336

Majedi, M. R., Afrazi, M., \& Fakhimi, A. (2020). A micromechanical model for simulation of rock failure under high strain rate loading. International Journal of Civil Engineering. https://doi.org/10.1007/s40999-020-00551-2

Mardookhpour, A., \& Ooshaksaraie, L. (2011). Advantages of utilizing geotextiles in fixing sandy soils and increasing shear strength in water conveyance trenches. American Journal of Geoscienced, 2(1), 1-3. https://doi.org/10.3844/ajgsp.2011.1.3

Mitchell, J. K., Houston, W. N., Scott, R. F., Costes, N. C., Carrier, W. D., \& Bromwell, L. G. (1972). Mechanical properties of lunar soil: Density, porosity, cohesion and angle of internal friction. Proceedings of the Lunar Science Conference, 3, 3235-3253.

Niroumand, H. (2017). Soil reinforcement for anchor plates and uplift response. Butterworth-Heinemann.

Perkins, S. W. (2007). The material properties of geosynthetics. Geosynthetics in Civil Engineering, 19-35. https://doi.org/10.1533/9781845692490.1.19
Prakasha, K. S., \& Chandrasekaran, V. S. (2005). Behavior of marine sand-clay mixtures under static and cyclic triaxial shear. Journal of Geotechnical and Geoenvironmental Engineering, 131(2), 213-222. https://doi.org/10.1061/(ASCE)10900241(2005)131:2(213)

Ranjkesh Adarmanabadi, H., Rasti, A., \& Razavi, M. (2020). Thermal image analysis of a cement kiln dust treated slope. International Journal of Science and Engineering Investigations, 9(107), 29-36. http://www.ijsei.com/papers/ijsei-910720-05.pdf

Ranjkesh Adarmanabadi, H., Rasti, A., \& Razavi, M. (2021). The effects of cement kiln dust on the soil electrical resistivity. American Journal of Engineering and Applied Sciences, 14(1), 51-63. https://doi.org/10.3844/ajeassp.2021.51.63

Rasti, A., Pineda, M., \& Razavi, M. (2020). Assessment of soil moisture content measurement methods: conventional laboratory oven versus halogen moisture analyzer. Journal of Soil and Water Science, $\quad 4(1)$ 151-160. https://doi.org/10.36959/624/440

Rouhanifar, S., Afrazi, M., Fakhimi, A., \& Yazdani, M. (2020). Strength and deformation behaviour of sand-rubber mixture. International Journal of Geotechnical Engineering, 1-15. https://doi.org/10.1080/19386362.2020.1812193

Rouse, P. C., Fannin, R. J., \& Shuttle, D. A. (2008). Influence of roundness on the void ratio and strength of uniform sand. Geotechnique, 58(3), 227-231. https://doi.org/10.1680/geot.2008.58.3.227

Sadrekarimi, A., \& Olson, S. M. (2011). Critical state friction angle of sands. Géotechnique, 61(9), 771-783. https://doi.org/10.1680/geot.9.P.090

Santamarina, J., \& Cho, G. (2001). Determination of critical state parameters in sandy soild-simple procedure. Geotechnical Testing Journal, 24(2), 185-192. https://doi.org/10.1520/GTJ11338J

Simoni, A., \& Houlsby, G. T. (2006). The Direct Shear Strength and Dilatancy of Sand-gravel Mixtures. Geotechnical \& Geological Engineering, 24(3), 523. https://doi.org/10.1007/s10706-004-5832-6

Vangla, P., \& Gali, M. L. (2016). Effect of particle size of sand and surface asperities of reinforcement on their interface shear behaviour. Geotextiles and Geomembranes, $\quad 44, \quad$ 254-268. https://doi.org/10.1016/j.geotexmem.2015.11.002

Vangla, P., \& Latha, G. M. (2015). Influence of particle size on the friction and interfacial shear strength of sands of similar morphology. International Journal of Geosynthetics and Ground Engineering, 1(1), 6 . https://doi.org/10.1007/s40891-014-0008-9 